\title{
Senior Citizens, Social Security, And Healthcare Costs
}

Robert E. Pritchard, Rowan University, USA

Gregory C. Potter, Rowan University, USA

\begin{abstract}
Based on an extensive literature review this paper discusses the interrelationships among the increasing numbers of Senior Citizens and the costs of Social Security and healthcare. This discussion includes information on Social Security pertaining to its funding and the Social Security Trust Funds. The paper notes that both the costs of Social Security and healthcare are directly related to improving healthcare. The ongoing improvements in healthcare result in increasing numbers of Senior Citizens who demand further improvements in healthcare. This leads to increases in longevity adding to healthcare and Social Security costs. Finally, the paper demonstrates the underlying complexities and the lack of consensus of possible changes to improve healthcare.
\end{abstract}

Keywords: Senior Citizens; Healthcare; Social Security; Longevity; Costs of healthcare

\section{INTRODUCTION}

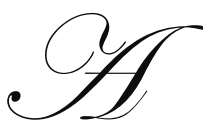

of two interactive processes that feed on each other.

lthough many reasons can be given for the rapidly increasing costs of Social Security and healthcare, there is one primary reason that trumps the others by a wide margin. Both Social Security and healthcare costs are increasing rapidly and will continue to do so primarily as a result

The first process is the ongoing rapid increase in the number of Senior Citizens (Americans 65 and older) and the slowly growing increase in their longevity. These two increases result primarily from improvements in healthcare. Demographic data discussed as a part of the Literature Review attests to the increase in the number of seniors, as well as the relative increase in costs attributable to the increase in the number of seniors and their increasing longevity. The Literature Review provides data indicating that, on a per capita basis, seniors are the primary recipients of healthcare.

The second process is the ongoing interaction between Senior Citizens (and older Baby Boomers) and the healthcare industry. As a consequence of the growth in the number of older Boomers and seniors and their increasing use of healthcare, the direction taken by the various stakeholders in the healthcare industry is now disproportionately targeted at meeting Senior Citizen and older-Boomer demands. Improvements in healthcare result in more people living longer. This stimulates demand (primarily by older people) for new and better medications, treatments, joint replacements, assisted living, nursing home facilities, and the like. In addition, the interactive process also increases demand for Social Security benefits.

Finally, the large and rapidly growing population of Senior Citizens not only comprises a rapidly growing market for the healthcare industry but, in addition, seniors have the power of the vote. Larger percentages of Senior Citizens vote than do members of any other age group; seniors cast nearly 20 percent of reported votes (U.S. Census 2010). As a group, they have significant political power.

\section{LITERATURE REVIEW}

The population of Senior Citizens is growing. The U.S. Census Bureau (2009) points to a tripling by midcentury of the world's 65-and-older population. Drawing on this data, Senior Journal (2009) reports that the "senior 
population [in America] appears to be headed to a 40 percent increase in the next five years" (p.1). As reported by Greenblatt in CQ Researcher (2007), one in five Americans will be over the age of 65 by 2050. "Such a profound demographic change," the article intones, "raises fundamental questions about the federal government's ability to pay for all the aging boomers who will be depending on Social Security, Medicare, and other entitlements" (p.868). A Centers for Medicare and Medicaid Services (2010) report on spending by age shows that Medicare enrollment growth is anticipated to be a stronger influence on future spending (1.6 percent growth per year from $2004-2050$ ) than the changing age-mix of the Medicare population, which will contribute just 0.1 percent per year.

In a special report on longevity, the Economist (2009) notes that throughout much of recorded history, the familiar biblical age of three score years and ten was rare. Average life expectancy was only 25 years during the first millennium. The significant change in life expectancy came with the industrial revolution that brought improvements in sanitation, nutrition, and disease control. Now, according to the Economist, some science and medical researchers suggest there may be no theoretical limit to life expectancy, as evidenced by the large growth in the number of centenarians over the past several decades.

Such a futuristic projection finds a degree of support from the new field of nanotechnology. Wiley (2005), a medical researcher and physician, writes that the structural "derangements" of aging and disease increasingly can be understood and controlled by nanotechnology, with the possibility of creating a "state of perfect molecular homeostasis" (p. S295).

But such longevity projections from medical science and engineering may collide with economics and social policy. An article in Money Management Executive (2009) quotes Social Demographer Wan He's remark that the "shift in the age structure of the world's population poses challenges to society, families, businesses, health care providers and policymakers to meet the needs of aging individuals." Kaufman (2009) remarks that cardiac procedures, organ transplantation, and cancer treatment represent medicine's triumphs in extending life but pose "existential" and "societal quandaries." A desire for therapeutics, Kaufman says, in an increasingly aging society, is turning older persons into medical consumers "questing after their own health and longevity" (p. 318). The existential reality of medical care is focused on the individual - the consumer - who seeks to diminish the risk of death by any clinical means available. New diagnostic tools, Kaufman elaborates, create a "perceived need" for providers and patients to intervene in slowing or stopping disease.

Inherent in this sociology of medical care is an assumption that perceived need translates into necessary delivery of medical services - a reality that does not regard costs or cost containment, since, Kaufman remarks, refusal of a procedure today may put one at risk for death later. Also, "hope is embodied" in these procedures (p. 324).

The calculus to which Kaufman refers involving life planning, risk reduction, state-of-the-art medical interventions, and the value of life itself is apparently confounding and likely to result in debates about medical care indefinitely. Taking but one quantifiable variable - age measurement - Shoven (2008) suggests that "gloomy projections" of a looming tidal wave of senior citizens are "deeply flawed" (p. 82). Changing the measurement of age by years since birth to a mortality risk measurement will reveal a far smaller demographic forecast for the "elderly wave" (p. 81). Governing benefits and retirements by mortality risk, according to Shoven, would make benefit costs far more realistic and manageable.

Pauly (2009) also implicitly challenges Kaufman's "indeterminate" debate by suggesting a new political strategy that specifies a "target-sustainable rate of growth of medical care spending" (p. 1472). The calculus would reckon cost-effectiveness ratios and a targeted growth amount for medical care spending. Innovations that "reduced costs and improved outcomes would all be included, followed by those with positive costs but relatively high benefits" (p. 1472).

Pauly's remarks relate to the broad medical philosophy and practice of so-called "evidenced-based medicine." Brownson et al (2009) argue that scientific evidence does not necessarily underpin the "real world" policy making. Policy making and debate may be framed around agendas that use numbers as "rhetorical weapons," they remark, rather than as empirical facts. 
Brownson et al's reference to "rhetorical" and "agendas" in the political realm relates to what Horton et al (2007) identify as the powerful cultural stereotypes that surround seniors. Issues of quality of life and longevity are embedded in cultural practices and viewpoints and ultimately affect cognitive and physical function of a population as it ages. Seniors with more optimistic outlooks, these researchers suggest, may take better care of themselves, with significant implications for how healthcare professionals and the industry care for this population.

Finally, there is the issue of per capita cost for healthcare by age. The Henry J. Kaiser Family Foundation (2006) reports the costs of healthcare by age group in 2006 as shown in Table I.

Table I: Distribution of Average Spending Per Person

\begin{tabular}{|c|c|}
\hline Age in Years & Average Spending per Capita \\
\hline$<5$ & $\$ 1,508$ \\
\hline $5-17$ & 1,267 \\
\hline $18-24$ & 1,441 \\
\hline $25-44$ & 2,305 \\
\hline $45-64$ & 4,863 \\
\hline$>64$ & 8,776 \\
\hline By Sex & $\$ 3,002$ \\
\hline Male & 3,886 \\
\hline Female & \\
\hline
\end{tabular}

The per capita cost of healthcare for seniors is over six times as great as the per The per capita cost of healthcare for seniors is over six times as great as the per capita cost for 18-24 year olds. This spread of costs is likely to increase over time because, as people age, they tend to develop multiple conditions that require costly treatments. The increasingly common but very expensive joint replacements, for example, are limited largely to older people. Similarly, most nursing homes and assisted living facility residents are seniors.

Finally, addressing the cost of healthcare, Alemayehu and Warner (2004) note that "nearly one-third of lifetime [healthcare] expenditures is incurred during middle age, and nearly half during the senior years. For survivors to age 85 , more than one-third of their lifetime expenditures will accrue in their remaining years.” (p. 627.)

\section{SOCIAL SECURITY AND THE SUPPORT OF SENIOR CITIZENS}

Fundamental economic analysis indicates that, in any society, those people who work support not only themselves, but everyone else. As a group, workers support themselves, their children, those who are unemployed or do not choose to work, those who are incarcerated, Senior Citizens - everybody.

It does not matter if Senior Citizens have accumulated great wealth that provides retirement income or manage only on Social Security. Once a person stops working (retires, is laid off, etc.) beyond what that individual does for her/himself, someone else has to provide the goods and services that person requires. Ultimately, the cost of providing for Senior Citizens is borne almost entirely by the productive component of the country's productive labor force (i.e., those who are employed).

Social Security - a primary source of income for nearly all Senior Citizens as well as many others - is facing a serious funding crisis. For many years Social Security taxes have exceeded benefit payments and operating expenses. Each year the excess taxes have been spent on defense, interest on the national debt, and other government expenses.

As the excess Social Security taxes were spent, the Government put Government IOUs (equaling the excess Social Security taxes revenues plus some interest) into the Social Security Trust Funds. There are trillions of dollars in Government IOUs in the Trust Funds.

Some might argue that future Social Security benefits can be paid out of the "paper wealth" Trust Funds. 
For this to take place, one or more of the following would have to take place. First, taxpayers (largely workers) would have to pay additional taxes to convert the Government IOUs into dollars that can be used to pay the Social Security benefits. Second, the Government would have to reallocate scarce resources to Social Security. Third, the Government would have to borrow more money (assuming lenders are available) to redeem the Trust Funds' IOUs. Fourth, the Government would have to print money and use it to redeem the Trust Funds' IOUs.

Considering the four alternatives noted above, one might easily conclude that neither the amount of Government IOUs in the Trust Funds nor any increase or depletion of the Trust Funds is relevant to the actual payment of Social Security benefits. In this light some have referred to Social Security as a Ponzi scheme (Social Security Online 2010).

As reported by the Social Security and Medicare Boards of Trustees (2009), the financial condition of the Social Security and Medicare programs remains challenging. They caution that "Social Security's annual surpluses of tax income over expenditures are expected to fall sharply for the year [2009] and to stay about constant in 2010 because of the economic recession, and to rise only briefly before declining and turning to cash flow deficits beginning in 2016 that grow as the baby boom generation retires."

Commenting on these projections by the Trustees, the E21organization (2009) remarked that the Trustees' projections have never been overly conservative; in fact, E21 comments, Trustees' projections have been "consistent and qualitatively accurate in light of subsequent data, with errors tending to be on the side of being slightly aggressive (meaning optimistic from the perspective of system financing)."

Finally, Social Security benefits are not guaranteed. The most fundamental challenge to the idea that Social Security benefits are guaranteed can be traced to the 1960 U.S. Supreme Court ruling in Flemming v. Nestor. The ruling states that benefits are not guaranteed and may be altered both in timing and amount at the discretion of the Government.

\section{DISCUSSION AND CONCLUSION}

One overarching relationship drives healthcare expenditures upward and increases the demand for Social Security: the ongoing interactive process of improving healthcare (that leads to ever greater demand for further healthcare improvements and higher healthcare costs) which, in turn, leads to the payment of Social Security benefits to greater numbers of Senior Citizens for longer periods as their longevity increases. This is a pressing economic and societal issue.

The question facing our society perhaps can be simply stated. Is it possible for our society to support current and future Senior Citizens and provide for their healthcare as their numbers continue to grow and their life expectancies increase without 1) overburdening the workforce with additonal taxes, 2) rationing healthcare and reducing Social Security and other payments to seniors, or 3) reallocating resources from other Government programs to support Senior Citizens? Addressing this question will require thorough evaluation of the costs and benefits of all alternatives.

Consider the following example. At present, the Veterans Administration (VA) may negotiate with pharmaceutical producers thereby reducing the cost of prescription drugs purchased by the VA. Current law precludes the Government from negotiating prescription drug prices for those covered by Medicare.

Suppose, as it has been suggested, that the Government was allowed to negotiate Medicare prescription drug prices. This is not a hypothetical issue. The Medicare Prescription Act of 2007 was designed to make this change. It was passed by the House but died in the Senate.

If the Government were allowed to negotiate Medicare prescription drug prices, in all likelihood their cost of drugs for Medicare recipients would decrease, perhaps significantly, thereby reducing healthcare costs. At the same time, however, the pharmaceutical producers' profits would likely decrease precipitating revisions to their business plans. 
One might expect the drug producers to reduce costly research. This would likely precipitate layoffs in the pharmaceutical industry. Concurrently, the pharmaceutical producers might refocus their research on the development of new and improved drugs that are targeted to younger segments of the population - those not covered by Medicare. That would represent a shift away from developing drugs that are largely targeted for aging Boomers and Senior Citizens.

If, in fact, pharmaceutical research were reduced and the remaining research funds redirected as suggested, a decrease in the rate of increase in longevity likely would result. Such a decrease would 1) decrease the rate of increase in all forms of healthcare provided to Senior Citizens as well as 2) decrease the rate of increase in life-long Social Security benefits paid to Senior Citizens.

It could be argued that the existing system of drug research and development of new and improved drugs has produced spectacular results and should not be changed. Others might argue for allowing the Government to negotiate with drug producers. But few likely would argue for taking measures to slow the current rate of increase in longevity. When stood on its head, supporting Government negotiations to reduce Medicare drug costs might be equated with "death panels."

Goetzel (2009) perhaps provides a useful perspective on the broad political, social, economic, and medical factors that underline population health. He notes that research in peer-reviewed literature suggests that most measures to prevent disease might not save money. Nor do medical treatments necessarily save money, he adds. A more productive approach, Goetzel argues, might be to determine the most cost-effective ways to achieve improved population health - where we can we get the most results for the dollar. Health promotion, in Goetzel's thinking, means the "science and art" of lifestyle changes, including the obvious ones such as not smoking and weight control. Especially in the context of the workplace, Goetzel suggests that employers have a built-in incentive to keep employees healthy.

In conclusion, Goetzel comments that in 2006, U.S. health spending exceeded two trillion dollars. Threefourths of that amount was for the treatment of chronic ailments, with two-thirds of the growth in spending attributable to worsening health habits, such as obesity. In this perspective, prevention, he argues, is a key element of comprehensive healthcare reform.

Goetzel provides an important perspective on the critical relationship between Social Security and the broader nexus of health and healthcare. The daunting complexities of healthcare in the United States clearly involve politics and stakeholders, including senior citizens. The nation eventually will have to make hard choices: who should receive benefits and under what schemes of administration, both public and private.

\section{AUTHOR INFORMATION}

Robert E. Pritchard, Ed.D., is a senior professor of finance in the Rohrer College of Business at Rowan University. He has authored and co-authored several books in the fields of finance and business management. He specializes in applied financial research and pedagogical research primarily pertaining to the teaching/learning process in business and finance. Dr. Pritchard earned a Doctorate in Educational Administration from the University of Pennsylvania and from Drexel University, a Master of Arts in Applied Economics, an MBA, and a Bachelor of Science in physics.

Gregory C. Potter, Ed.D., is Associate Dean of Library Services at Rowan University, where he coordinates library instruction and information literacy programs. He has collaborated with Rowan University faculty in published research on academic assessment, pedagogy, and career development programs. Dr. Potter earned a Doctorate in the Foundations of Education from Rutgers University, a Master of Science in Library Science from Villanova University, a Master of Arts in public relations from Rowan University, and a Bachelor of Arts in English from the University of Pennsylvania. 


\section{REFERENCES}

1. Alemayehu, B. \& Warner. K. (2004). The lifetime distribution of health care costs. Health Services Research, 39(3), 627-642.

2. Brownson, R., Chriqui, J., \& Stamatakis, K. (2009). Understanding evidence-based public health policy. American Journal of Public Health, 99(9), 1576-1584.

3. Centers for Medicare and Medicaid Services (2010). NHE Factsheet; U.S. health spending by age highlights. Retrieved from http://www.cms.hhs.gov/NationalHealthExpendData/25_NHE_Fact_

4. Economist (2009). A world of methuselahs (special report, June 27, 2009). Retrieved from http://www.lexisnexis.com.

5. $\quad$ E21 - Economics for the $21^{\text {st }}$ Century (2009). Social Security's grim milestone: Half a year in the red. Retrieved from http://www.economics21.org/commentary/social-securitys-grim-milestone-half-year-red.

6. Goetzel, R. (2009). Do prevention or treatment services save money? The wrong debate. Health Affairs, 28(1), 37-41.

7. $\quad$ Greenblatt, A. Aging baby boomers. CQ Researcher, 17(37), 865-888.

8. Henry J. Kaiser Family Foundation (2006). Kaiser Slides. Retrieved from http://facts.kff.org/chart.aspx?ch=856.

9. Horton, S., Baker, J. \& Deakin, J. (2007). Stereotypes of aging: Their effects on the health of seniors in North American Society. Educational Gerontology, 33, 1021-1035.

10. Kaufman, S. (2009). Making longevity in an aging society: Linking ethical sensibility and Medicare spending. Medical Anthropology, 28(4), 317-324.

11. Money Management Executive (2009). U.S. older population to reach $20 \%$ by 2030. Money Management Executive, 17(26), 8.

12. Pauly, M. (2009). Is it time to reexamine the patent system's role in spending growth? Health Affairs, 28(5), 1466-1474.

13. Senior Journal.com (2009). Senior citizen population on brink of explosion in world and in United States: Census Bureau. Retrieved from http://www.seniorjournal.com/NEWS/SeniorStats/2009/20090624-.

14. Shoven, J. (2008). New age thinking. Foreign Policy, Issue 164, 82-84.

15. Social Security Administration (2009). Fast facts and figures, 2009. Retrieved from http:// www.ssa.gov/policy/docs/chartbooks/fast facts/index.html.

16. Social Security Online (2009). Status of the Social Security and Medicare Programs (Trustees Summary 2009). Retrieved from http://www.socialsecurity.gov/OACT/TRSUM/index.html.

17. Social Security Online (2010). Ponzi schemes vs. Social Security (Research Note \#25). Retrieved from Social Security Online. http://www.ssa.gov/history/ponzi.htm.

18. U.S. Census Bureau (2009). Census Bureau reports world's population projected to triple by 2050. Retrieved from U.S. Census Bureau News Service, Tuesday, June 23, 2009, http://www.census.gov/PressRelease/www/releases/archives/intern.

19. Wiley, C. (2005). Nanotechnology and molecular homeostasis (paper presented Teaneck, April 2004). JAGS (Journal of the American Geriatric Society), 53:S295-S298. 